\title{
Overweight and obesity in children and adolescents with chronic autoimmune thyroiditis
}

\author{
Ana P. González-Mereles*, Sletza L. Arguinzoniz-Valenzuela, Ana P. López-López, Silvia E. Maqueda- \\ Tenorio, and Iñaki González-Baqué \\ Servicio de Endocrinología, Instituto Nacional de Pediatría, Mexico City, Mexico
}

\begin{abstract}
Background: An association between overweight and thyroid dysfunction, including chronic autoimmune thyroiditis (CAT), has been previously described. Patients with overweight and obesity have a higher risk of increased thyroid-stimulating hormone (TSH) and anti-thyroid antibodies. Weight gain may also be a clinical sign of hypothyroidism. This study aimed to describe the frequency of overweight and obesity in children with CAT and to compare thyroid function and antibody titles according to body weight. Methods: Clinical records from 78 patients with CAT who were followed up at a children's hospital in Mexico City were assessed. We collected demographic, anthropometric, and biochemical data, including thyroid function tests and antibodies. According to body mass index (BMI) percentiles, patients were classified as normal weight, overweight or obese according to BMI percentiles. Also, BMI changes at 6 and 12 months of follow-up were analyzed. Results: We observed $19.2 \%$ of the patients with overweight and $15.4 \%$ with obesity. Patients with obesity showed high TSH and low thyroid hormone levels. Also, the frequency of hypothyroidism at presentation was higher in this group. No significant difference was found in antibody titles between groups. A significant BMI percentile reduction was observed during follow-up of patients independently of thyroid function at diagnosis and treatment. Conclusions: Obesity is related to hypothyroidism in patients with chronic autoimmune thyroiditis, although causality cannot be established through this observational study.
\end{abstract}

Keywords: Hashimoto disease. Hypothyroidism. Overweight. Obesity. Pediatrics.

\section{Sobrepeso y obesidad en niños y adolescentes con tiroiditis crónica autoinmunitaria}

\section{Resumen}

Introducción: Previamente se ha identificado una asociación entre el sobrepeso y las alteraciones tiroideas, incluyendo la tiroiditis crónica autoinmunitaria (TCA). Los pacientes con sobrepeso y obesidad presentan elevación de la hormona estimulante de la tiroides (TSH) y mayor frecuencia de anticuerpos antitiroideos. Por otro lado, el incremento de peso es un síntoma clásico de hipotiroidismo. El objetivo del trabajo es describir la frecuencia de sobrepeso y obesidad en pacientes con TCA, y comparar la función tiroidea y los anticuerpos antitiroideos según el peso corporal. Métodos: Se recolectaron datos demográficos, antropométricos y bioquímicos, pruebas de función tiroidea y anticuerpos antitiroideos, de 78 pacientes con TCA atendidos en un hospital pediátrico en la Ciudad de México. Se clasificaron en subgrupos, de acuerdo con el

\section{Correspondence:}

*Ana P. González Mereles

E-mail: pediatria.endo@gmail.com
Available online: 17-09-2021

Bol Med Hosp Infant Mex. 2021;78(5):424-431

www.bmhim.com 1665-1146/@ 2021 Hospital Infantil de México Federico Gómez. Published by Permanyer. This is an open access article under the CC BY-NC-ND license (http://creativecommons.org/licenses/by-nc-nd/4.0/). 
percentil del índice de masa corporal (IMC), como peso normal, sobrepeso y obesidad. Se analizó el comportamiento del IMC a los 6 y 12 meses de los pacientes incluidos. Resultados: El 19.2\% de los pacientes presentaron sobrepeso y el $15.4 \%$ obesidad. Se encontraron valores mayores de TSH y menores de hormonas tiroideas en los pacientes con obesidad, quienes presentaron con mayor frecuencia hipotiroidismo al diagnóstico. No se encontraron diferencias significativas en el título de anticuerpos entre los grupos. Durante el seguimiento se observó una disminución significativa en el percentil del IMC en los pacientes, sin diferencias según el tratamiento recibido ni la función tiroidea al diagnóstico. Conclusiones: La obesidad se asocia con hipotiroidismo como patrón bioquímico inicial en los pacientes con TCA.

Palabras clave: Enfermedad de Hashimoto. Hipotiroidismo. Sobrepeso. Obesidad. Pediatría.

\section{Introduction}

Chronic autoimmune thyroiditis (CAT) or Hashimoto's thyroiditis is the most frequent cause of acquired hypothyroidism and goiter in countries where iodine intake is adequate. A prevalence ranging from $1.2-3 \%$ has been reported in the pediatric age, being more frequent in adolescent females, with a mean age of presentation between 10 and 12 years ${ }^{1-8}$.

CAT pathophysiology is characterized by infiltration of the thyroid gland by $T$ and $B$ lymphocytes resulting in cytotoxicity, apoptosis, and release of pro-inflammatory cytokines and antibodies directed against thyroid antigens such as thyroglobulin (Tg-Ab), thyroid peroxidase enzyme (TPO-Ab), thyroid-stimulating hormone (TSH) receptor, sodium-iodine transporter, and pendrin ${ }^{3,5,9}$.

CAT is a disease of multifactorial origin resulting from the combination of environmental factors in genetically predisposed subjects. An increased risk has been described in patients with $H L A-B^{*} 46: 01, H L A-A^{*} 02: 07$, and HLA-DRB4 haplotypes and with polymorphisms in the CTLA-4, CD40, PTPN22, and IL2R genes ${ }^{9}$.

Environmental factors associated with CAT development include a diet high in iodine, hepatitis $C$ virus and herpes virus type 6 infection, smoking, radiation, and the use of drugs such as lithium, tyrosine kinase inhibitors, amiodarone, interferon-alpha, and alemtuzumab ${ }^{3,5,9,10}$.

Some studies have found an increased prevalence of CAT in overweight patients, and those with CAT and obesity have high antithyroid-antibody levels. However, the direction of causality of this association is unclear $^{1,9,10}$. In one aspect, weight gain is usually one of the most characteristic symptoms of hypothyroidism. Conversely, overweight and obesity cause an increase in leptin levels, which through the hypothalamic POMC/ CART (pro-opiomelanocortin/cocaine- and amphetamine-regulated transcript) pathway stimulates the synthesis of thyrotropin-releasing hormone (TRH) $3,9,11,12$. Furthermore, it has been proposed that leptin also has immunomodulatory functions and that overweight produces a systemic inflammatory state that may favor the appearance of autoimmune diseases ${ }^{1,10,13,14}$.

This study aimed to determine the frequency of overweight and obesity in children and adolescents with chronic autoimmune thyroiditis and its distribution according to thyroid function at diagnosis and to evaluate whether there are differences in the levels of Tg-Ab, TPO-Ab, TSH, and thyroid hormones between patients with overweight, obesity, and normal-weight. Moreover, the changes in body mass index (BMI) at 6 and 12 months of follow-up were studied, comparing the variations between those who started treatment with levothyroxine at the first visit and those who did not receive pharmacological treatment regarding their initial thyroid function.

\section{Methods}

We conducted an observational, longitudinal, retrospective study in which we reviewed the records of patients aged 2 to 18 years with a diagnosis of CAT seen in the Endocrinology service of the Instituto Nacional de Pediatría (National Institute of Pediatrics, INP) in Mexico City from January 2016 to January 2019. A case of CAT was defined as any patient with antibodies against thyroglobulin or thyroid peroxidase ( $\mathrm{Tg}-\mathrm{Ab}$ and TPO-Ab, respectively) and alterations in thyroid function tests or presence of goiter. Patients with systemic autoimmune disease, patients with treatments or pathologies associated with an increased risk of CAT (Down syndrome, Turner syndrome, type 1 diabetes mellitus, celiac disease, and history of neck radiation), as well as individuals with excess weight caused by medications (glucocorticoids) or systemic diseases were excluded.

A total of 78 cases met the inclusion criteria. Demographic data, anthropometric data (weight and height), thyroid profile, Tg-Ab, TPO-Ab levels (measured by immunochemiluminescence), requirement or not of treatment, and levothyroxine dose at diagnosis 


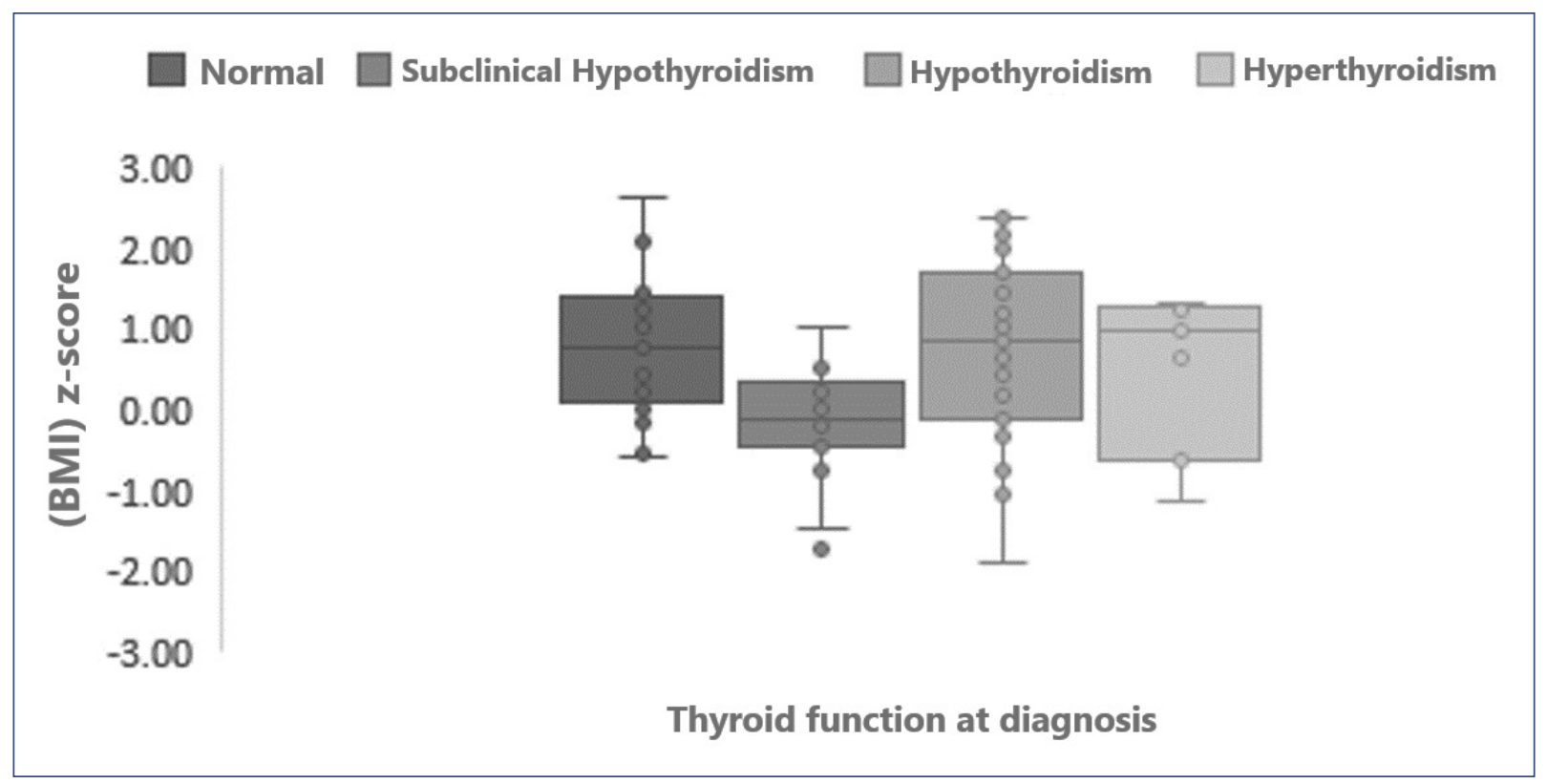

Figure 1. Body mass index (BMI) Z-score according to thyroid function at diagnosis. According to the thyroid function at diagnosis, there is a statistical difference in BMI Z-score ( $p=0.025$ obtained by Kruskal-Wallis test for independent samples). Post hoc analysis showed differences between patients with subclinical hypothyroidism and hypothyroidism $(p=0.029)$ and between those with standard thyroid profiles and subclinical hypothyroidism $(p=0.045)$.

and 6 and 12 months of follow-up were collected. Patients were classified according to thyroid function at diagnosis using the following criteria:

Hypothyroidism: Thyroid hormones below the normal lower limit or a TSH $\geq 20 \mathrm{mIU} / \mathrm{L}$.

Subclinical hypothyroidism: TSH values $>4$ but $<20 \mathrm{mlU} / \mathrm{L}$ and thyroid hormones within normal ranges.

Euthyroidism: $\mathrm{TSH} \leq 4 \mathrm{mIU} / \mathrm{L}$ and thyroid hormones within laboratory reference ranges.

Hyperthyroidism: Thyroid hormones above the normal upper limit or a TSH $\leq 0.4 \mathrm{mIU} / \mathrm{L}$.

BMI was calculated, and the Z-score and percentiles of $\mathrm{BMI}$ and height were estimated using the Center for Disease Control and Prevention (CDC) growth charts.

Nutritional status was classified according to the Endocrine Society criteria: overweight, BMl between $85^{\text {th }}$ to $94^{\text {th }}$ percentile; obesity, BMI above $95^{\text {th }}$ percentile ${ }^{15,16}$.

Short stature was defined as a height-for-age and gender Z-score $\leq 2 \mathrm{SD}$.

Regarding antibodies directed against thyroid antigens, the laboratory upper detection limit is $3000 \mathrm{IU} / \mathrm{mL}$ for Tg-Ab and $1000 \mathrm{IU} / \mathrm{mL}$ for TPO-Ab. Therefore, higher values are reported as $>3000 \mathrm{IU} / \mathrm{mL}$ and $>1000 \mathrm{IU} / \mathrm{mL}$, respectively. On this basis, we decided to analyze antibody titer as a categorical variable; TPO-Ab titers were classified into three groups: low $(<500 \mathrm{IU} / \mathrm{mL})$, intermediate (500-999 IU/mL), and high ( $\geq 1000 \mathrm{IU} / \mathrm{mL})$. Also, Tg-Ab titers were classified into low $(<500 \mathrm{IU} / \mathrm{mL})$, intermediate (500-2999 IU/mL), and high ( $\geq 3000 \mathrm{IU} / \mathrm{mL})$.

Statistical analysis was conducted using the SPSS program. Descriptive statistics were performed to characterize the sample and estimate the frequency of overweight and obesity in the study population and the frequency of thyroid function alterations at diagnosis. ANOVA and Kruskal-Wallis tests were performed to compare TSH and thyroid hormone levels and $\chi^{2}$ tests to compare antibody titers according to baseline thyroid function. Pearson's $\chi^{2}$ test was used to assess the distribution of excess weight according to baseline thyroid function. A two-factor repeated-measures ANOVA test was used to assess the change in BMI percentile at 6 and 12 months after diagnosis. Statistical significance was considered at a $p$-value $<0.05$.

\section{Results}

Of the 78 cases included in the study, 70 were females (89.7\%) and eight males (10.3\%), with an 8.7:1 ratio. The mean age at diagnosis was $10.8 \pm 3.01$ years, with a minimum age of 3 years 4 months. A total of $52.6 \%$ of patients showed puberty signs at the time of 
Table 1. Clinical and biochemical features according to thyroid function at diagnosis

\begin{tabular}{|c|c|c|c|c|c|}
\hline & $\begin{array}{l}\text { Euthyroidism } \\
\qquad(\mathrm{n}=17)\end{array}$ & $\begin{array}{l}\text { Subclinical hypothyroidism } \\
\qquad(\mathrm{n}=15)\end{array}$ & $\begin{array}{l}\text { Hypothyroidism } \\
\quad(n=39)\end{array}$ & $\begin{array}{l}\text { Hyperthyroidism } \\
\qquad(\mathrm{n}=7)\end{array}$ & $\mathbf{p}^{*}$ \\
\hline Age (years) & $11.5 \pm 2.8$ & $11.5 \pm 1.9$ & $9.9 \pm 3$ & $12.4 \pm 3.7$ & 0.056 \\
\hline Age $<10$ years & $5(29.4 \%)$ & $4(26.7 \%)$ & $21(53.8 \%)$ & $1(14.3 \%)$ & $0.073 \bullet$ \\
\hline Prepuberal & $5(31.2 \%)$ & $5(33.3 \%)$ & $24(61.5 \%)$ & $2(28.6 \%)$ & $0.072 \bullet$ \\
\hline F:M & $7.5: 1$ & $14: 1$ & $6.8: 1$ & $6: 1$ & $0.540 \bullet$ \\
\hline Height Z-score & $-0.47 \pm 0.84$ & $-0.46 \pm 0.59$ & $-1.31 \pm 1.7$ & $-0.77 \pm 1.23$ & 0.111 \\
\hline BMI $\left(\mathrm{kg} / \mathrm{m}^{2}\right)$ & $19.2(15.6-38.7)$ & $17.5(13.6-21.8)$ & $18.4(13.9-35.9)$ & $22.03(14.4-24.9)$ & 0.225 \\
\hline BMI Z-score & $0.76(-0.6-+2.65)$ & $-0.11(-1.74-+1.02)$ & $0.84(-1.88-+2.4)$ & $0.99(-1.14-+1.31)$ & $0.025^{1}$ \\
\hline TSH (mUl/L) & $2.69(0.55-3.97)$ & $5.26(4.1-15.6)$ & 75 (12.3-75) & $0.01(0.004-0.17)$ & 0.000 \\
\hline FT4 (ng/dL) & $1.21 \pm 0.11$ & $1.05 \pm 0.24$ & $0.55 \pm 0.25$ & $1.65 \pm 0.75$ & 0.000 \\
\hline $\begin{array}{l}\text { TG-Ab (\%) } \\
<500 \mathrm{UI} / \mathrm{mL}\end{array}$ & $64.3 \%$ & $78.6 \%$ & $62.5 \%$ & $100 \%$ & $0.277 \bullet$ \\
\hline 500-2999 UI/mL & $35.7 \%$ & $7.1 \%$ & $28.1 \%$ & $0 \%$ & \\
\hline$\geq 3000 \mathrm{UI} / \mathrm{mL}$ & $0 \%$ & $14.3 \%$ & $9.4 \%$ & $0 \%$ & \\
\hline $\begin{array}{l}\text { TPO-Ag (\%) } \\
<500 \mathrm{UI} / \mathrm{mL}\end{array}$ & $60 \%$ & $37.5 \%$ & $23.5 \%$ & $40 \%$ & 0.226 \\
\hline 500-999 UI/mL & $0 \%$ & $7.1 \%$ & $17.6 \%$ & $20 \%$ & \\
\hline$\geq 1000 \mathrm{UI} / \mathrm{mL}$ & $40 \%$ & $57.1 \%$ & $58.8 \%$ & $40 \%$ & \\
\hline
\end{tabular}

*Obtained by analysis of variance and Kruskal-Wallis test according to the distribution of the data.

- Obtained by $\chi^{2}$ test.

${ }^{1}$ Post hoc analysis showed differences between patients with subclinical hypothyroidism and hypothyroidism ( $\mathrm{p} 0.029$ ) and between those with standard thyroid profiles and subclinical hypothyroidism (p 0.045).

BMI, body mass index; F:M, female:male ratio; FT4, free thyroxine; TG-Ab, antibodies against thyroglobulin; TPO-Ag, antibodies against thyroid peroxidase; TSH, thyroid-stimulating hormone.

Table 2. Frequency of overweight and obesity concerning thyroid function at diagnosis

\begin{tabular}{|l|c|c|c|c|} 
& $\begin{array}{c}\text { Euthyroidism } \\
(\mathbf{n}=\mathbf{1 7})\end{array}$ & $\begin{array}{c}\text { Subclinical hypothyroidism } \\
(\mathbf{n}=\mathbf{1 5})\end{array}$ & $\begin{array}{c}\text { Hypothyroidism } \\
(\mathbf{n}=39)\end{array}$ & $\begin{array}{c}\text { Hyperthyroidism } \\
(\mathbf{n}=7)\end{array}$ \\
\hline Normal weight* $(\%)$ & $9(52.9 \%)$ & $14(93.3 \%)$ & $24(61.5 \%)$ & $4(57.1 \%)$ \\
\hline Overweight* $(\%)$ & $6(35.3 \%)$ & $1(6.7 \%)$ & $5(12.8 \%)$ & $3(42.9 \%)$ \\
\hline Obesity* $(\%)$ & $2(11.8 \%)$ & $0(0 \%)$ & $10(25.6 \%)$ & $0(0 \%)$ \\
\hline
\end{tabular}

*Classification of nutritional status according to the criteria of the Endocrine Society ${ }^{15}$

There is a significant difference in the frequency of normal weight, overweight and obesity in relation to thyroid function at diagnosis ( $p=0.021$ obtained by Pearson's $\chi^{2}$ test).

presentation. In addition, a family history of thyroid pathology was reported in $25.6 \%$ of the individuals.

The most frequent reasons for consultation were the presence of goiter and symptoms of hypothyroidism, although $8 \%$ of the patients went for evaluation to address overweight or obesity. During the first consultation, $19.2 \%$ of the patients were short according to standard population parameters; the median height Z-score was -0.57 (-5.24 to 1.74$)$.
Regarding thyroid function at diagnosis, 38 patients had hypothyroidism (48.7\%), 16 had subclinical hypothyroidism $(20.5 \%), 17$ had normal thyroid function $(21.8 \%)$, and 7 had hyperthyroidism (9\%). Table 1 summarizes the clinical and biochemical characteristics of the patients according to baseline thyroid function.

A statistically significant difference was found in the median BMI Z-score according to baseline thyroid function $(p=0.025)$. The post hoc analysis showed that 


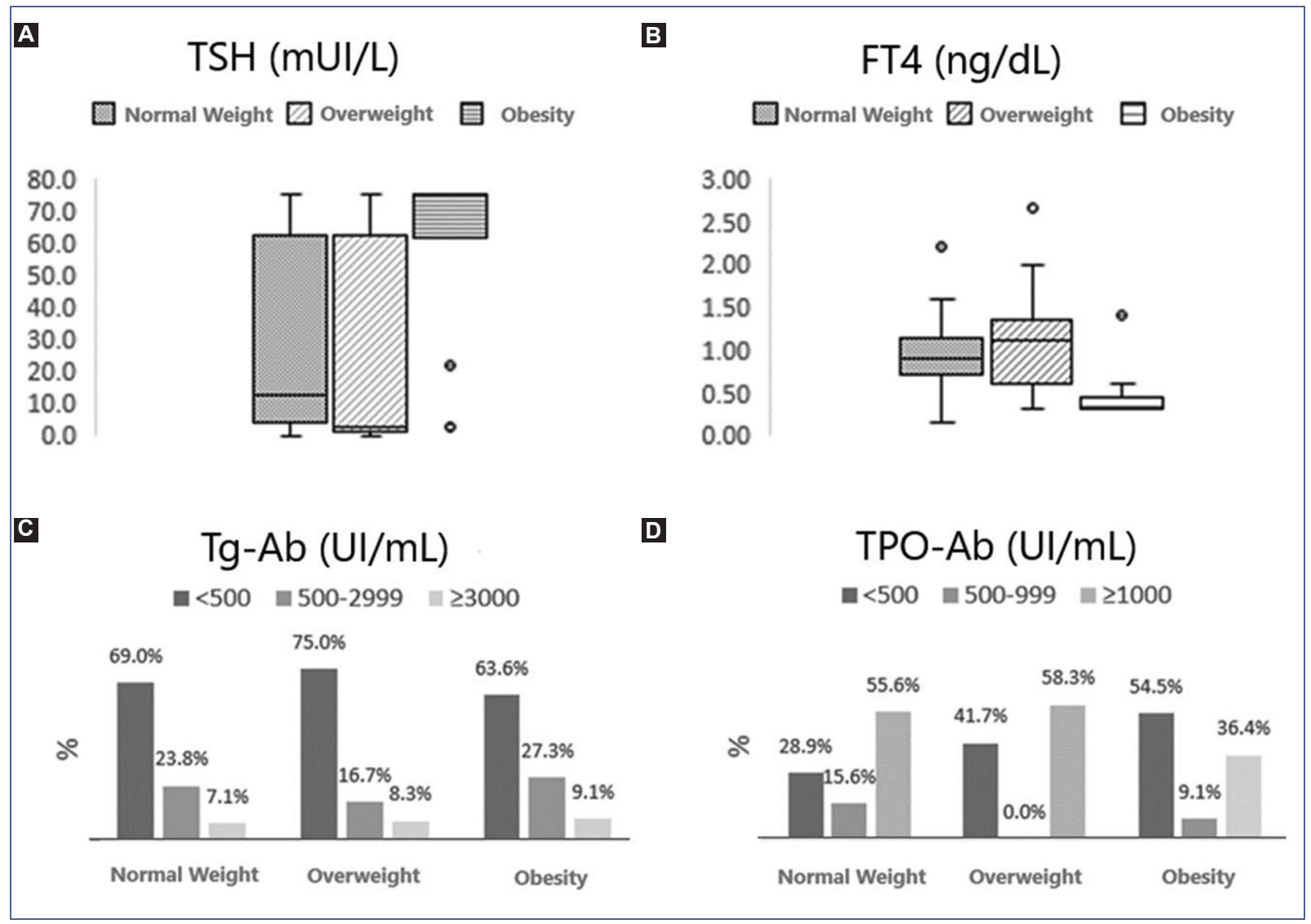

Figure 2. Biochemical profile at diagnosis according to nutritional status. A: patients with obesity presented higher TSH levels ( $p=0.009$ obtained by Kruskal-Wallis test). B: lower levels of FT4 ( $p=0.001$ obtained by Kruskal-Wallis test) than patients with normal weight and overweight. C: the Tg-Ab titer at diagnosis was similar between groups $(p=0.977$ obtained by the $\chi^{2}$ test). D: patients with obesity presented more frequently low titers $(<500 \mathrm{IU} / \mathrm{mL}$ ) and less frequently high titers $(\geq 1000 \mathrm{IU} / \mathrm{mL})$ of TPO-Ab than patients with overweight and normal weight, the difference was not significant $\left(p=0.338\right.$ obtained by test $\left.\chi^{2}\right)$.

$\mathrm{Ab}$, antibodies; FT4, free plasma thyroxine; Tg, thyroglobulin; TP0, thyroperoxidase enzyme.

BMI Z-score was lower in patients with subclinical hypothyroidism than in those with hypothyroidism $(p=0.029)$ and normal thyroid function $(p=0.045)$ (Figure 1).

We found a frequency of overweight of $19.2 \%$ and obesity of $15.4 \%$ in the population studied, with a combined prevalence of overweight + obesity of $34.6 \%$.

The frequency of overweight and obesity was different between groups, with a higher proportion of overweight in patients with hyperthyroidism, while obesity was more common in those with hypothyroidism $(p=0.021)$ (Table 2).

Eighty percent of patients with obesity at diagnosis presented hypothyroidism compared with $42 \%$ of the non-obesity group $(p=0.009)$. Patients in the obesity group had higher TSH levels $(p=0.009)$ and lower free plasma thyroxine (FT4) ( $p=0.001)$ and triiodothyronine (T3T) $(p=0.003)$ than the overweight and normal-weight groups. No differences were found in $\mathrm{Tg}$-Ab titers according to nutritional status $(p=0.97)$. Although patients with obesity presented more frequently low $(<500 \mathrm{IU} / \mathrm{mL})$ and less frequently high TPO-Ab titers ( $\geq$ $1000 \mathrm{IU} / \mathrm{mL}$ ) when compared with the overweight and normal-weight groups, this difference was not statistically significant $(p=0.338)$ (Figure 2$)$.

Levothyroxine treatment was initially used in 61 patients: 39 with hypothyroidism, 13 with subclinical hypothyroidism, and nine with normal thyroid function. The mean initial dose of levothyroxine was $2.18 \pm 0.65$ $\mu \mathrm{g} / \mathrm{kg} /$ day. Seventeen patients did not receive medical treatment, including seven patients with hyperthyroidism, two patients with subclinical hypothyroidism, and eight with standard thyroid function tests at diagnosis.

A repeated-measures ANOVA test was performed, showing a statistically significant decrease in BMI 

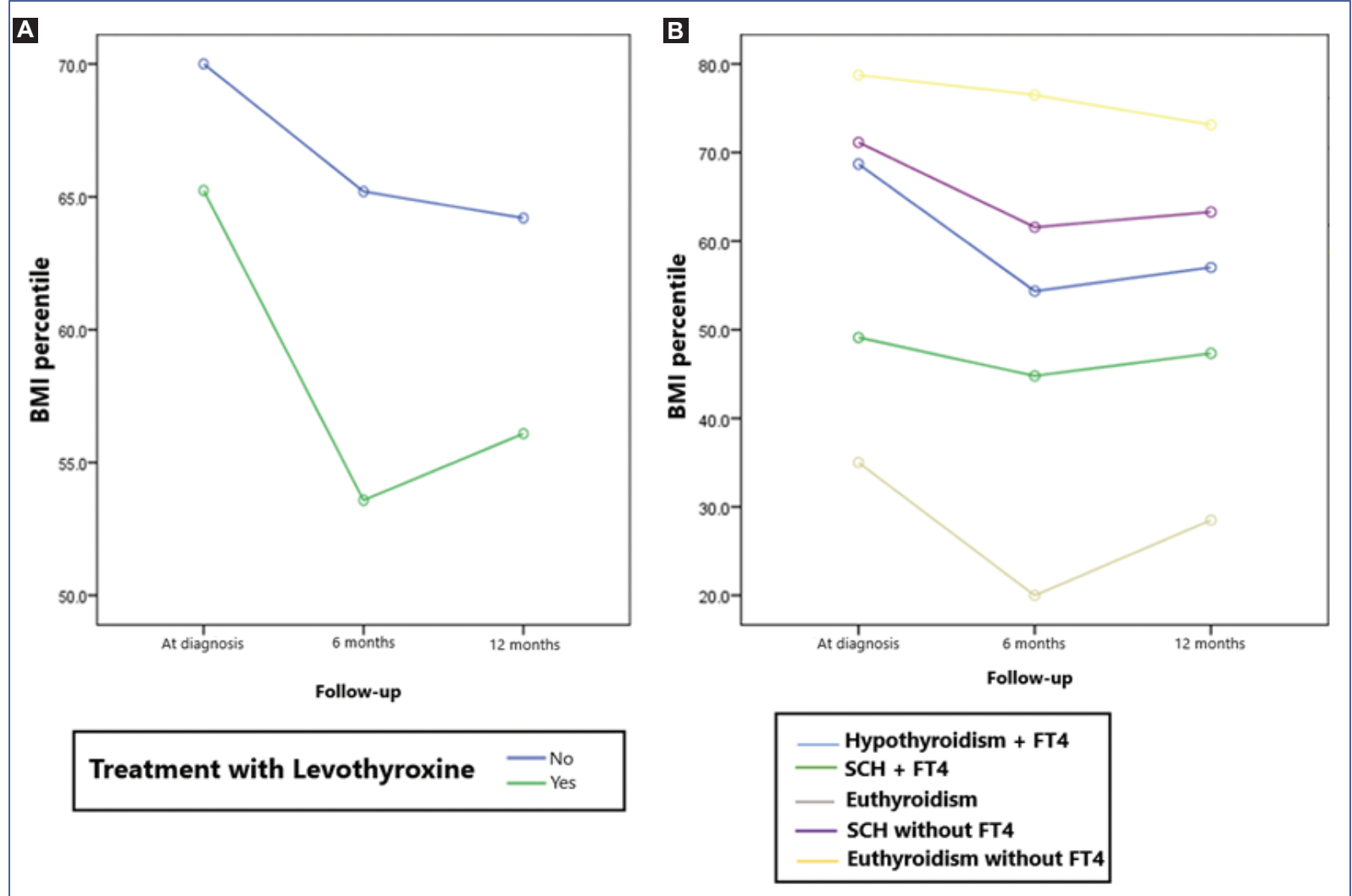

Figure 3. A: changes in body mass index (BMI) percentile during follow-up according to treatment. Repeated measures analysis of variances showed a decrease in BMI percentile at 6 and 12 months after diagnosis $(p=0.016)$; however, no significant difference was observed between those who received initial treatment with levothyroxine and the rest of the patients $(p=0.456)$. B: BMI percentile changes according to treatment and thyroid function at diagnosis. No significant difference was found when comparing patients according to thyroid function at diagnosis and treatment received $(p=0.625)$.

FT4, free plasma thyroxine; SCH, subclinical hypothyroidism.

*This analysis does not include patients with hyperthyroidism at diagnosis. Treatment with levothyroxine was initiated in 61 patients: 39 with hypothyroidism, 13 with subclinical hypothyroidism, and nine with normal thyroid function. Two patients with subclinical hypothyroidism and eight with normal thyroid function did not receive pharmacological treatment.

percentile at 6 months and 12 months $(p=0.016)$. However, no significant difference was observed between those who received initial treatment with levothyroxine and the rest of the patients $(p=0.456)$. A subgroup analysis was performed according to thyroid function at diagnosis and the received management, but no statistically significant differences were found in BMI percentile changes $(p=0.625)$ (Figure 3).

\section{Discussion}

In pediatrics, most CAT cases are diagnosed in females during adolescence. In accordance with other authors, our cohort shows greater prevalence of TCA in females (89.7\% vs. $10.3 \%)$ and the appearance of secondary sexual characteristics in more than half of the cases at the time of diagnosis $5,6,17,18$.

Regarding different pediatric case series, patients with CAT usually present with normal thyroid function (21-63\%) or subclinical hypothyroidism (19-47\%) 4,17,18. This study shows that obesity is associated with higher levels of TSH and lower levels of thyroid hormones. We need to emphasize that our hospital is a tertiary care center, where complex and mostly referral cases are treated. Therefore, a selection bias in our sample could be possible, increasing the frequency of hypothyroidism at diagnosis.

Due to the significant increase in overweight and obesity and their complications in the pediatric 
population worldwide, it is essential to have timely detection of both pathologies. Our observations (19.2\% prevalence of overweight and $15.4 \%$ of obesity) reflect the current situation in our country, where $20 \%$ and $14 \%$ of children between 5 and 19 years of age show overweight and obesity, respectively ${ }^{19,20}$. In addition, our cohort of patients with a diagnosis of CAT showed a higher obesity rate in those with hypothyroidism at diagnosis.

In the medical literature, a bidirectional relationship between excess weight and autoimmune thyroid disease has been proposed. First, hypothyroidism may favor weight gain by reducing the basal metabolic rate; second, obesity and increased leptin levels play an immunomodulatory and pro-inflammatory role that triggers autoimmunity. Furthermore, the excess weight alone can elevate TSH levels even in the absence of autoimmunity markers, thus increasing the controversy between the cause-effect role of each player ${ }^{1,3,9-14,21}$.

Other authors have reported an increased risk of hypothyroidism in individuals with overweight and obesity. For example, a recent meta-analysis by Song et al. that included 22 studies of children and adults with excess weight found a relative risk of hypothyroidism of 3.1 in patients with obesity, while the risk of subclinical hypothyroidism was reported to be $1.7^{22}$. In the present study, we found that $80 \%$ of patients with CAT and obesity presented hypothyroidism at diagnosis compared with $33 \%$ of patients with overweight and $47 \%$ of subjects with normal weight.

The factors that determine the biochemical pattern in CAT at diagnosis are not fully understood; however, it has been suggested that younger age and prepubertal status at presentation may be associated with the presence of hypothyroidism ${ }^{23}$. In this study, we observed that hypothyroidism was found in younger patients at the time of diagnosis and more frequently in the prepubertal stage, although no statistical significance was observed. Our findings indicate that obesity is associated with hypothyroidism as an initial biochemical pattern in patients with autoimmune thyroiditis; the same effect was not observed in patients with overweight.

Valea et al. compared TSH and thyroid hormone levels in a group of adults with CAT and classified them according to their BMI, showing higher TSH levels and lower levels of $\mathrm{T} 3$ and $\mathrm{T} 4$ in patients with excess weight ${ }^{1}$. As observed in adults, the group of patients with obesity in our study presented higher TSH levels and lower levels of free T3T and FT4.

Other authors have reported higher levels of TPO-Ab in patients with overweight and obesity ${ }^{1,22}$. On the contrary, in our study, patients with obesity presented TPO-Ab levels in lower ranges than those with normal weight and overweight, although the difference was not significant. One of the main limitations of this analysis was the laboratory's upper detection limit that did not allow analyzing antibody levels as a quantitative variable.

Another important finding was the significant decrease in BMI percentile at 6 and 12 months in the studied individuals, which was similar between groups regardless of treatment and thyroid function. Treatment with levothyroxine in patients with CAT without hypothyroidism is not indicated; however, it is used in patients with significant goiter or frankly elevated or steadily rising anti-thyroid antibody titers in many centers. Although an increased risk of progression to hypothyroidism has been described in patients with high titers of anti-thyroid antibodies, and treatment with levothyroxine has been shown to decrease titers in some studies, no clinical benefit from this practice has been demonstrated $^{8,24}$. Our findings indicate that levothyroxine does not improve body composition in patients with CAT. Therefore, the presence of overweight or obesity should not be used as a parameter to decide the initiation of levothyroxine treatment.

Weight loss is likely to be observed in all groups during follow-up, as hygienic-dietary modifications are part of the treatment offered to every patient with CAT in our clinic, reinforcing the importance of hygienic dietary modifications in the comprehensive treatment of patients with CAT.

In addition to cardiometabolic complications classically associated with excess weight, thyroid disorders, including CAT, appear to be related to overweight and obesity.

It is known that patients with overweight and obesity have a higher risk of presenting antibodies against thyroid antigens. This study shows that obesity is associated with high levels of TSH and low levels of thyroid hormones, and a high frequency of hypothyroidism as an initial biochemical pattern in children and adolescents with CAT. The use of levothyroxine in patients with chronic autoimmune thyroiditis does not have a significant effect on body composition and, therefore, the presence of overweight or obesity does not justify its use in patients without hypothyroidism. Although this observational study does not resolve the dilemma of the directionality of the effect, it reinforces and confirms a significant association between the two variables.

Further high-quality research is required to determine the direction of causality between excess weight and 
autoimmune thyroiditis and issue recommendations on thyroid function assessment in patients with obesity. Therefore, this study could be considered as an initial step in direction.

\section{Ethical disclosures}

Protection of human and animal subjects. The authors declare that no experiments were performed on humans or animals for this study.

Confidentiality of data. The authors declare that they have followed the protocols of their work center on patient data publication.

Right to privacy and informed consent. The authors have obtained the written informed consent of the patients or subjects mentioned in the article. The corresponding author has this document.

\section{Conflicts of interest}

The authors declare no conflict of interest.

\section{Funding}

None.

\section{References}

1. Valea A, Carsote M, Moldovan X, Georgescu C. Chronic autoimmune thyroiditis and obesity. Arch Balk Med Union. 2018;53:64-9.

2. Mincer DL, Jialal I. Hashimoto Thyroiditis. In: StatPearls. Treasure Island (FL): StatPearls Publishing. 2021. Available from: https://www.ncbi.nlm. nih.gov/books/NBK459262

3. Radetti G. Clinical aspects of Hashimoto's thyroiditis. Endocr Dev 2014;26:158-70.

4. Crisafulli G, Gallizzi R, Aversa T, Salzano G, Valenzise M, Wasniewska M, et al. Thyroid function test evolution in children with Hashimoto's thyroiditis is closely conditioned by the biochemical picture at diagnosis. Ital $\mathrm{J}$ Pediatr. 2018;44:22.

5. Díaz A, Lipman EG. Hypothyroidism. Pediatr Rev. 2014;35:336-49.

6. Brown R. Autoimmune thyroiditis in childhood. J Clin Res Pediatr Endocrinol. 2013;5(Suppl 1):45-9.
7. Demirbilek H, Kandemir N, Gonc E, Ozon A, Alikasifoglu A. Assessment of thyroid function during the long course of Hashimoto's thyroiditis in children and adolescents. Clin Endocrinol (Oxf). 2009;71,451-4.

8. Radetti G, Maselli M, Buzi F, Corrias A, Mussa A, Cambiaso P, et al. The natural history of the normal/mild elevated TSH serum levels in children and adolescents with Hashimoto's thyroiditis and isolated hyperthyrotropinaemia: a 3-year follow-up. Clin Endocrinol (Oxf). 2012;76:394-8.

9. Ajjan R, Weetman A. The pathogenesis of Hashimoto's thyroiditis: further developments in our understanding. Horm Metab Res. 2015;47:702-10.

10. Marzullo P, Minocci A, Tagliaferri M.A, Guzzaloni G, Di Blasio A, De Medici $C$, et al. Investigations of thyroid hormones and antibodies in obesity: leptin levels are associated with thyroid autoimmunity independent of bioanthropometric, hormonal, and weight-related determinants. $\mathrm{J}$ Clin Endocrinol Metab 2010;95:3965-72.

11. Versini $M$, Jeandel $P$, Rosenthal $E$, Shoenfeld $Y$. Obesity in autoimmune diseases: not a passive bystander. Autoimmun Rev. 2014;13:981-1000.

12. Sidhu S, Parikh T, Burman KD. Endocrine Changes in Obesity. In: Feingold KR, Anawalt B, Boyce A, Chrousos G, de Herder WW, Dhatariya K, et al., editors. Endotext. South Dartmouth (MA): MDText.com, Inc; 2000 Available from: https://www.ncbi.nlm.nih.gov/books/NBK279053/

13. Matarese G, Leiter E, La Cava A. Leptin in autoimmunity: many questions, some answers. Tissue Antigens. 2007;70:87-95.

14. De Rosa V, Procaccini C, Calì G, Pirozzi G, Fontana S, Zappacosta S, et al. A key role of leptin in the control of regulatory $T$ cell proliferation. Immunity. 2007;26:241-55.

15. Styne DM, Arslanian SA, Connor EL, Farooqi IS, Murad MH, Silverstein $\mathrm{JH}$, et al. Pediatric obesity-assessment, treatment, and prevention: an Endocrine Society clinical practice guideline. J Clin Endocrinol Metab. 2017;102:709-57.

16. Altamirano-Bustamante NF, Altamirano-Bustamante MM, Valderrama-Hernández A, Montesinos-Correa H. La evaluación del crecimiento. Acta Pediatr Mex. 2014;35:238-48.

17. Skarpa V, Kousta E, Tertipi A, Anyfandakis K, Vakaki M, Dolianiti M, et al Epidemiological characteristics of children with autoimmune thyroid disease. Hormones (Athens). 2011;10:207-14.

18. De Vries L, Bulvik S, Phillip M. Chronic autoimmune thyroiditis in children and adolescents: at presentation and during long-term follow-up. Arch Dis Child. 2009;94:33-7.

19. World Health Organization. Datos y cifras sobre obesidad infantil. Informe de la Comisión para acabar con la obesidad infantil. Geneva: World Health Organization; 2016. Available from: https://apps.who.int/iris/bitstream/handle/10665/206450/9789243510064_spa.pdf?sequence=1\&isAllowed=y

20. Shamah-Levy T, Cuevas-Nasu L, Gaona-Pineda E, Gómez-Acosta L, Morales-Rúan $M$, Hernández-Ávila $M$, et al. Sobrepeso y obesidad en niños y adolescentes en México: actualización de la Encuesta Nacional de Salud y Nutrición de Medio Camino 2016. Salud Publica Mex. 2018;60:244-53.

21. Radetti G, Kleon W, Buzi F, Crivellaro C, Pappalardo L, di lorgi N, et al. Thyroid function and structure are affected in childhood obesity. J Clin Endocrinol Metab. 2008;93:4749-54.

22. Song RH, Wang B, Yao QM, Li Q, Jia X, Zhang J. The impact of obesity on thyroid autoimmunity and dysfunction: a systematic review and meta-analysis. Front Immunol. 2019;10:2349.

23. Wasniewska M, Corrias A, Salerno M, Mussa A, Capalbo D, Messina M, et al. Thyroid function patterns at Hashimoto's thyroiditis presentation in childhood and adolescence are mainly conditioned by patients' age. Horm Res Paediatr. 2012;78:232-6.

24. Lee HS, Hwang JS. The natural course of Hashimoto's thyroiditis in children and adolescents. J Pediatr Endocr Metab. 2014;27(9-10):807-12. 